\title{
Activated Sludge Growth under LED Illumination
}

\author{
Mahmudul Kabir, Ryutaro Miura, Masafumi Suzuki, and Noboru Yoshimura
}

\begin{abstract}
The excess activated sludge production is the main problem of activated sludge method in waste water treatment plants. Several researches are being carried out to control the excess sludge production. Sludge growth process is a major factor to control the sludge production. Several observations are carried out to learn the information of sludge growth under several circumstances. One of the process was to observe the effect of light on sludge production performed by other researchers. Recently, the light emitting diode (LED) illumination is being used in different purposes including vegetable plantation. Here, we have observed sludge growth under LED illumination process with aerobic SBR plants. The white, blue and red LED illumination (each of 2 types) were used and the activated sludge growth and their waste water treatment abilities were investigated. We did not find any difference in $\mathbf{p H}$, chemical oxygen demand (COD) removal in the activated sludge under LED illumination. But significant differences were found in sludge growth and sedimentation properties of activated sludge. Floc construction was disturbed by red/ blue LED illumination. It degraded the SV30 characteristics of the activated sludge. We have found that the growth of activated sludge was effected due to the different frequencies of LED illumination.
\end{abstract}

Index Terms-Activated sludge growth, COD removal, LED illumination, sedimentation,

\section{INTRODUCTION}

Activated sludge growth holds a great interest as it is the main method to treat waste water in most of the developed countries including Japan. The main problem of this method is the production of excess sludge. Every year a large amount of excess activated sludge is being produced in the Waste Water Treatment Plants (WWTPs). It is a great problem in both economical and environmental aspects. Several processes are carried out in several countries to reduce excess sludge in water treatment [1-6]. The sludge growth is also a focus of interest among the scientists and several reports are available to observe the activated sludge growth $[7,8]$. Recently, the use of light emitting diode (LED) on plants' growth is increasing. There are reports on LED illumination's effect on indoor plantation [9]. Fukuda showed with different frequencies of LED illumination on Petunia that Petunia's growth as well as flowering was affected by different frequencies of LED. Again, research work of light illumination on anaerobic activated sludge is available [10], however, the LED illumination on activated

Manuscript received November 26, 2012; revised December 29, 2012.

M. Kabir, R. Miura and M. Suzuki are with the Department of Electrical and Electronic Engineering, Graduate School of Engineering and Resource Science, Akita University, 1-1, Tegata Gakuenmachi, Akita-shi, Akita 010-8502, Japan (e-mail: kabir@ ipc.akita-u.ac.jp).

N. Yoshimura is with Akita University, 1-1, Tegata Gakuenmachi, Akita-shi, Akita 010-8502, Japan. sludge growth has not been reviewed. Again, the activated sludge consists of both flora and fauna microorganisms. So, it can be expected that the activated sludge can be affected by LED illumination like plants. Here, we have observed the activated sludge growth under different frequencies of LED light (i.e. different color of LED illumination) in laboratory scale. LEDs are smaller in size and they are good for environment for lower energy consumption and longer lifetime. They have also greater durability and reliability comparing to the existing illumination systems.

First, we will describe about the process of activated sludge growth in a WWTP briefly. Fig.1 shows the model diagram of a WWTP. The waste water after some pretreatment is supplied to the aeration tank where the activated sludge is kept. Air is supplied there and the waste water is purified by oxidation reaction. Then the water comes to the settling tank with some activated sludge. The supernatant liquid and activated sludge are separated naturally there. After some tests, it is released to the river or sea. The settled sludge is taken to the aeration tank as return sludge. The excess sludge is taken out from the line if necessary and taken under several treatments before burn. The amount of excess sludge is calculated with the next equation $[7,8]$,

$$
\Delta X=\mathrm{a} S_{\mathrm{r}}-\mathrm{b} X
$$

Here,

$\mathrm{a}=$ gross yield coefficient of sludge

$S_{\mathrm{r}}=$ BOD removal; $Q_{\mathrm{I}} \times C_{\mathrm{I}} \times\left(C_{\mathrm{I}}-C_{\mathrm{O}}\right) / C_{\mathrm{I}}[\mathrm{kg} / \mathrm{d}]$

$\mathrm{b}=$ Specific biomass decay due to self oxidization [1/d]

$X=$ amount of activated sludge $[\mathrm{kg}]$

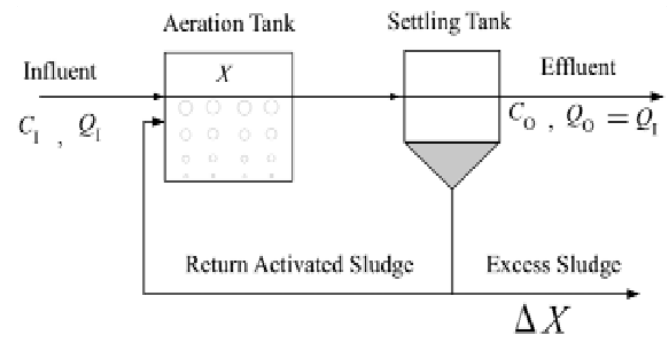

Here,

$$
\begin{aligned}
& C_{\mathrm{I}}: \text { BOD of waste water }\left[\mathrm{kg} / \mathrm{m}^{3}\right] \\
& Q_{\mathrm{I}}: \text { amount of influent }\left[\mathrm{m}^{3} / \mathrm{d}\right] \\
& Q_{0}: \text { amount of effluent }\left[\mathrm{m}^{3} / \mathrm{d}\right] \\
& C_{0}: \text { BOD of effluent }\left[\mathrm{kg} / \mathrm{m}^{3}\right] \\
& X \text { : amount of activated sludge }[\mathrm{kg}] \\
& \Delta X \text { :excess sludge }[\mathrm{kg} / \mathrm{d}]
\end{aligned}
$$

Fig. 1. Model diagram of waste water treatment in WWTPS.

The equation shows that the production of excess sludge depends on the value of "a" and "b" for a plant. In order to 
decrease the excess sludge, increasing of "b" is a method, but a lot of electricity is needed which is costly. Another factor is to regulate the parameter "a" which is not so easy to conduct. In this research we have maintained the parameter " $b$ ” is to be constant for every plant.

We have approached to observe the effect of LED illumination on activated sludge growth with different types (size, shape and frequency) of LED illumination [11]. This paper describes the effect of LED illumination on Activated sludge growth during waste water treatment in laboratory scale. We have found definite change in sludge amount and sedimentation properties due to the different frequency of LED illumination during the experiment by LED illumination on activated sludge.

\section{EXPERIMENTAL METHOD}

The growth of activated sludge was observed by miniature Sequencing Batch Reactors (SBR). The reactors were prepared with non-transparent plastic bottles. The size of a miniature SBR is $140 \times 260 \mathrm{~mm}$ and the capacity of the plant is 3L. An air stone and a transparent tube were set up in each miniature SBR plant. The size of the transparent tube is $20 \times 220 \mathrm{~mm}$. This tube was well sealed so that the activated sludge cannot enter into the tube. LED illumination system is dangled in this tube. The schematic diagram of a SBR with illumination system can be seen in Fig. 2. A certain amount of activated sludge is kept in this plant. The seed activated sludge was taken from the Yabase Sewage Treatment Plant of Akita city, Japan. The seed activated sludge was cultured in miniature WWTPs run at Suzuki Lab. of Akita University. The MLSS was $3000-4000 \mathrm{mg} / \mathrm{L}$ of the sludge and their COD removal efficiency was about $94 \%$ while run at miniature plants in the laboratory. The whole plant was kept on a water bath (TR-2A, AS ONE, Co.) so that the plant did not get any effect of temperature varying during the experiment period. Maximum 4 treatment plants can be setup in the same water bath at a time. A black curtain covered all the 4 plants to avoid other light. 2 types of LED illuminations were applied to these plants. They were bullet type and surface mount diode (SMD) type. First, we will describe about the bullet type LED bulbs. They were as follows; a) red (LK-5RD-C50; $1.56 \mathrm{~cd}$ ), b) blue (LK-5BL-C50; 3.00cd) and c) white (LK-5WH-C50; 8.40cd). The general size of these LED bulbs was same. The diameter of a bulb is $5 \mathrm{~mm}$ and length is $25 \mathrm{~mm}$. The LED bulbs were produced by EK Japan Co., Ltd. The electric current is $15 \mathrm{~mA}$ of this LED bulbs and the directivity is $30^{\circ}$.

The SMD type LED bulbs were made by Audio Q, Japan. They were also white, red and blue in color. The size of SMD LED is $7.6 \times 7.6 \mathrm{~mm}$. The bulbs are d) white (AQ-MPF05140WC), e) red (AQ-MPF05140RC) and f) blue (AQ-MPF05140BC). The luminosity values of these bulbs are 25,18 and $5 \mathrm{~cd} / \mathrm{sr}$, respectively at the Iave of $150 \mathrm{~mA}$. The values of frequency of red and blue are 620 630 and 455 475, respectively. The directivity is $140^{\circ}$ for all the SMD bulbs. 2 sets of 4 bulbs were connected in parallel circuit on 2 electric boards. The 2 sets of same LED were set up in a way that they illuminate the plant from every direction.

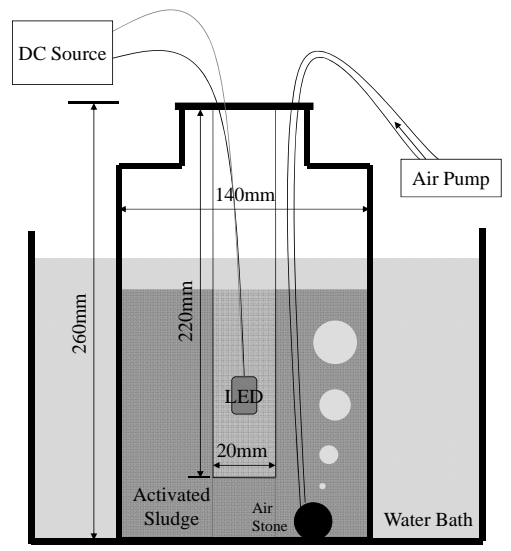

Fig. 2. Model diagram of an SBR plant with illuminating system

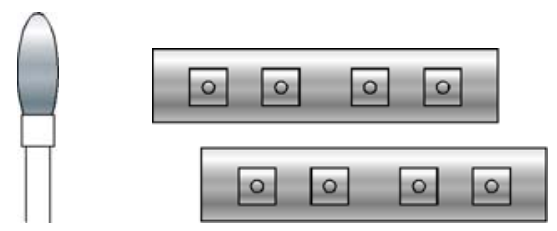

(a) bullet type

(b) SMD LED

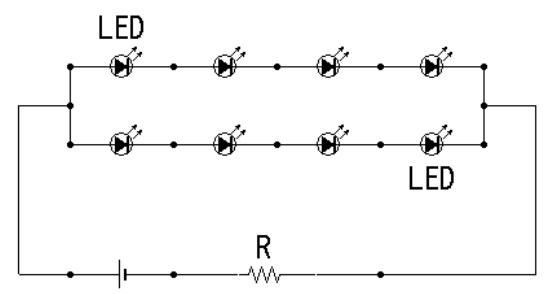

(c) circuit with SMD LED

Fig. 3. Different LEDs and the circuit model

The LED bulbs and circuit can be seen in Fig. 3. The temperature was monitored during the experiment period by a thermometer (CT-450WR, CUSTOM). The voltage power was provided by 2 DC voltage source (AD-8723D, A\&D Co., PAB32-1.2, Kikusui Co.).

Table I shows the parameters used in the experiments. LED illumination was applied for $24 \mathrm{~h}$ a day. The supernatant liquid was removed from the plants and an amount of influent $(1 \mathrm{~kg} / \mathrm{d})$ was provided in each container at $11 \mathrm{am}$ and $3 \mathrm{pm}$, respectively. The ingredients of the influent were as follows; a) peptone $0.5 \mathrm{~g} / \mathrm{L}$, b) glucose $0.5 \mathrm{~g} / \mathrm{L}$, c) East $0.25 \mathrm{~g} / \mathrm{L}$, d) Ammonium dihydrogen phosphate (NH $4 \mathrm{H} 2 \mathrm{PO} 4$ ) 7mg/L and 5) $25 \%$ Ammonia water $1 \mathrm{~mL} / \mathrm{L}$. These chemical products are available in the markets. Fig. 4 shows the chart for the SBR process in this research work. At first, 2L of activated sludge whose MLSS was adjusted at $2000 \mathrm{mg} / \mathrm{L}$, was taken to a reactor. 4 sequencing reactors could be used at a time. The reactors were kept without any air supply for precipitation for $4 \mathrm{~h}$. After that, $1 \mathrm{~L}$ of the supernatant liquid of each SBR plant was removed. Then $1 \mathrm{~L}$ of influent was added in each plant. The measurement of BOD takes time comparing to that of COD, so we preferred to measure the easier one, i.e. COD in this experiment, although the COD and BOD are not equal literally. We prepared the influent of the plants manually each day and measured their COD values before adding them to the plants. The aeration time was fixed at $8 \mathrm{~h} / \mathrm{d}$. After it, the plants were kept for precipitation for 
TABLE I: THE FACTORS FOR THE EXPERIMENTS

\begin{tabular}{|l|l|}
\hline observation period & $9 \mathrm{~d}$ \\
\hline temperature of SBR & 30 ? ${ }^{\circ} \mathrm{C}$ \\
\hline illumination time & $24 \mathrm{~h} / \mathrm{d}$ \\
\hline volume of activated sludge & $2 \mathrm{~L} / \mathrm{SBR}$ plant \\
\hline initial value of MLSS & $2000 \mathrm{mg} / \mathrm{L}$ \\
\hline amount of influent & $1 \mathrm{~L} / \mathrm{d}$ \\
\hline aeration period & $8 \mathrm{~h} / \mathrm{d}$ \\
\hline aeration amount & $1 \mathrm{~L} / \mathrm{min}$. \\
\hline
\end{tabular}

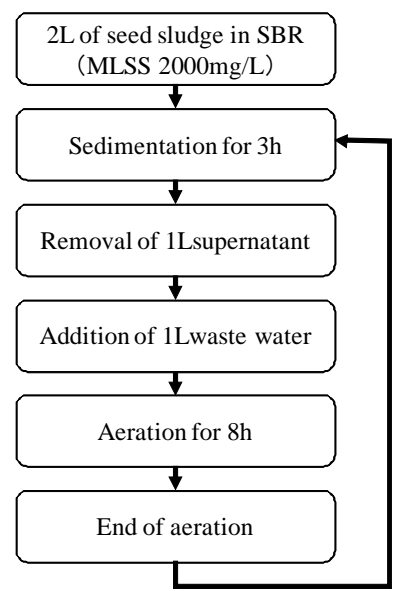

Fig. 4. Model diagram of the laboratory apparatus.

3-4h and thus the cycle continued during the experiment period. In our experiments, we performed measurements of MLSS (Mixed Liquor Suspended Solids), SV $_{30}$ (Sludge Volume) and $\mathrm{pH}$ of the activated sludge. The values of $\mathrm{pH}$ and MLSS were measured by a pH meter (S211, Horiba) and MLSS meter (SS-5F, Kasahara Chemical Instruments Co., Ltd.), respectively. We also measured the Chemical Oxygen Demand (COD) of the supernatant liquid for each plant. The COD values of influent and supernatant liquid were measured by a COD meter (HC-607, Central Kagaku Co.). Then we calculated the COD removal efficiency by the following equation;

\section{COD removal efficiency [\%]}

$=($ CODinfluent - CODeffluent $) \times 100 /$ CODinfluent

Again, we calculated the sludge volume index (SVI) for each measurements of $\mathrm{SV}_{30}$ in each plant with following equation;

$$
\begin{aligned}
& \text { SVI [mL/g] } \\
& \quad=\mathrm{SV}_{30} \times 1000 / \text { MLSS of the relevant plant }
\end{aligned}
$$

The observations were carried out for 9d. Due to the problem of space, we performed the experiments in twice different period with different LEDs. At first, white LEDs with another plant which was equipped without any source of light (i.e. dark condition) were used. Then the red and blue LEDs were used. We also measuered the viable cell of each plant and observed the activated sludge by an optic microscpe (Nikon; Eclipse L150) regularly. The vicinity cell of the activated sludge was measured by Easicult T.T.C. (Orion Diagnostica) test tubes regularly. The Easicult T.T.C. is a test tube with a slide of agar to culture the microbes. After culturing the microbes of the activated sludge for $24-48 \mathrm{~h}$ at $28^{\circ} \mathrm{C}$ in a constant temperature and humidity chamber, the viable cell number in $1 \mathrm{~mL}$ solution can be found by comparing with the model chart provided by Orion Diagnostica.

\section{Results AND Discussions}

We observed the temperature of the SBR plants on the water bath cautiously. The results are not shown here but the temperature was found always same for all the containers in the water bath during our measurement period. Even the placement of the container in the water bath did not affect the temperature of the miniature SBRs. There was no visual difference in the activated sludge of the sequencing plants. The results are not shown here but there was no significant change in the viable cells of activated sludge of the 4 plants. Again no significant change was found in the values of $\mathrm{pH}$ of the activated sludge during the observation period.

We measured the values of COD for supernatant liquid for each plant. Then we caluculated the COD removal and COD removal efficiency of the plants. These values are plotted on Fig.5 and Fig.6, respectively. Fig. 5 shows the relation between the COD influent and COD removal of the plants. We can see that there is no significant difference with this relation regarding on the LED illumination. COD removal was increasing linearly with COD influent. All the plants showed linear relation between COD influent and COD removal. Thus, the activated sludge of different SBR plants showed similar COD removal ability in spite of LED illumination. This fact insists that the growth of activated sludge in each SBR plant would be similar as the COD removal was the only supply of nutrients for these SBR plants. A part of COD removal contributes to the sludge growth. Fig. 6 shows the COD removal efficiency of the activated sludge under different illumination. One can see that the COD removal efficiency is definitely different under different types of illumination condition. However, the MLSS values varied with different LED illuminations. For all the miniature plants, the starting MLSS values were $2000 \mathrm{mg} / \mathrm{L}$, but they reached to 2800, 2700 and $2700 \mathrm{mg} / \mathrm{L}$ respectively for dark, white bullet and white SMD plants. The average values of MLSS were 2485.7, 2414.3 and $2414.3 \mathrm{mg} / \mathrm{L}$ respectively. The standard deviation values for MLSS were 254.5, 219.3 and $219.3 \mathrm{mg} / \mathrm{L}$ respectively. At the second time of the experiment, the initial values of MLSS were equal to $2000 \mathrm{mg} / \mathrm{L}$, too. But on the 9th day, it reached to 3000,3000 , 2700 and $2800 \mathrm{mg} / \mathrm{L}$ for red bullet, red SMD, blue bullet and blue SMD. Figure 7 shows the growth of activated sludge in our experimental period. Thus the growth rate of the activated sludge was different in different SBR plants though their experimental condition was similar except the type of illumination. One thing to be noted that the values of COD for influent were not same for these two sets of experiments for different types of illumination conditions. The values of COD influent of the plants were different as the experiments could not be performed in a single time. The influent was processed with the necessary ingredients described at "Experimental Method" carefully, but is easy to understand 


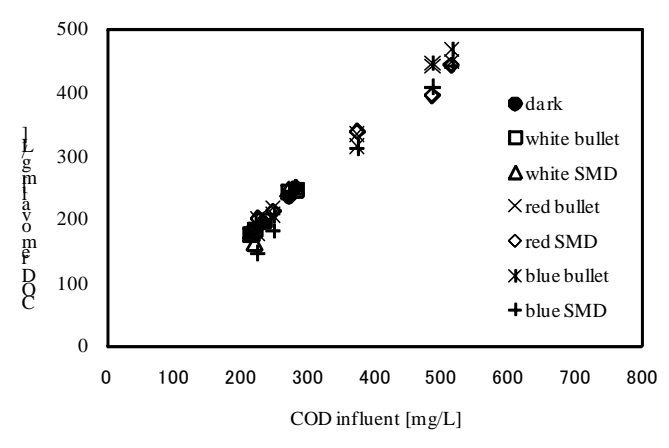

Fig. 5. COD removal-COD influent relation.

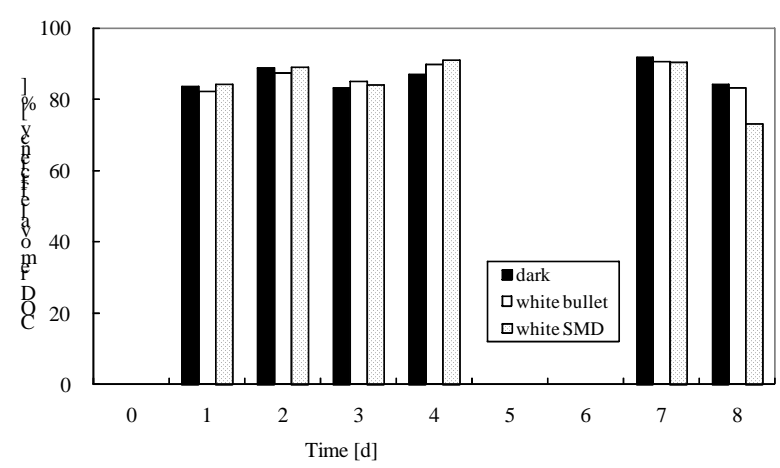

(a) COD removal efficiency

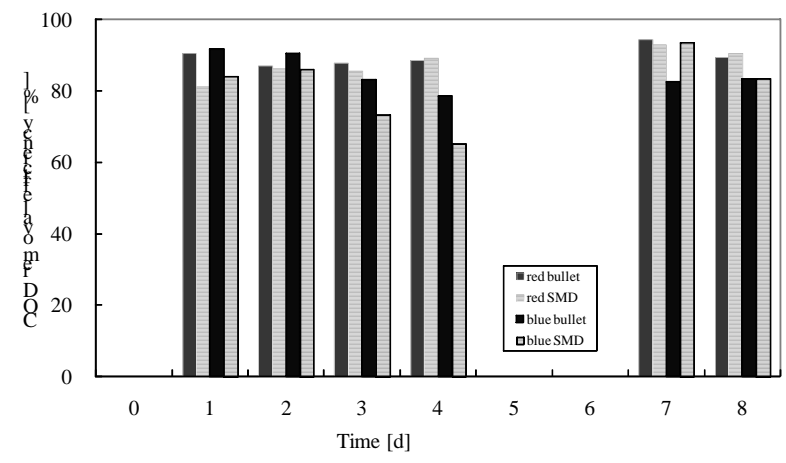

(b) COD removal efficiency

Fig. 6. COD removal efficiency of the SBR plants

that it is difficult to prepare the influent with same COD values manually. We prepared the influent each day during our observation and measured the COD of it before adding to the SBR plants. Thus there was difference in COD values of influent. This might be a reason for the difference in growth rate in the plants. Figure 5 also showed that the amount of COD removal for red and blue LEDs' plants were higher than that of the dark and white LED illuminations'. And, the values of Fig.7 (b) reflect the COD removal amounts in MLSS values of the relevant plants. We investigated the measured data more vividly. So, we calculated the standard deviations of COD removal efficiency for each plant. The average sludge growth was also calculated for the plants. Again, the average yield of sludge (sludge growth/ COD removal) was calculated for each plant to understand the grwth of activated sludge under LED illumination. The calculated results can be found in Table2. For COD removal efficiency, the values in bracket show the standard deviation values of the relevant plants. If we compare the values of COD removal with sludge growth of the same table, we can understand that COD removal contributed to sludge growth most in the case of dark condition. It can also be verified by the values of yield of the sludge. It is to be noted that the sludge growth was smaller in the presence of LED illumination despite of the larger COD removal values comparing to the activated sludge of dark condition. It

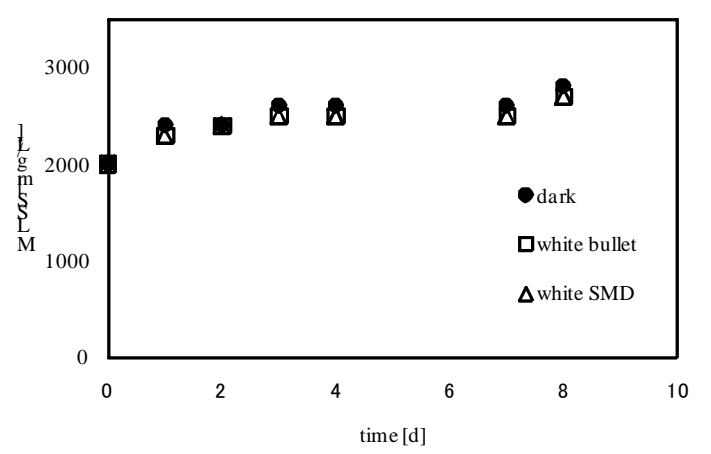

(a) MLSS values

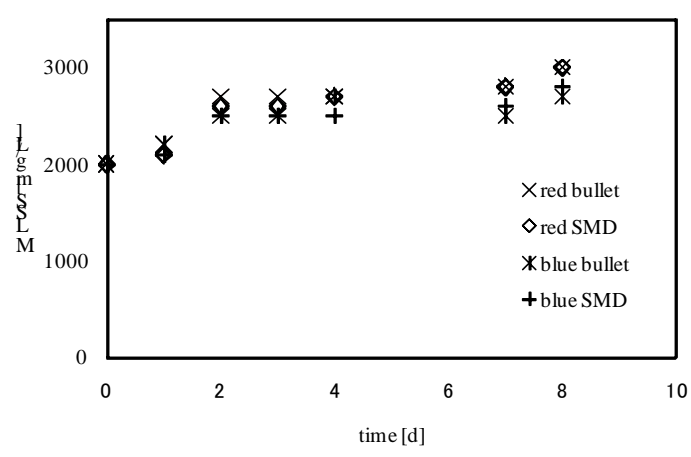

(b) MLSS values

Fig. 7. MLSS values of the SBR plants

indicates that LED illumination can be a kind of stress to the activated sludge. Though we need more experiments and observations to perform in order to understand the effect of LED illumination on activated sludge growth.

We measured the $\mathrm{SV}_{30}$ for all the plants. The SVI values for each plant was also calculated using the $\mathrm{SV}_{30}$ values with dividing them by their MLSS values. Fig. 8 shows the values

TABLE II: DIFFERENCES IN SLUDGE GROWTH UNDER LED ILLUMINATION

\begin{tabular}{|l|c|c|c|c|c|c|c|}
\hline \multirow{2}{*}{} & \multirow{2}{*}{ dark } & \multicolumn{2}{|c|}{ white } & \multicolumn{2}{|c|}{ red } & \multicolumn{3}{|c|}{ blue } \\
\cline { 3 - 9 } & & bullet & SMD & bullet & SMD & bullet & SMD \\
\hline average COD removal [mg/L·d] & 130.7 & 131.0 & 129.5 & 205.0 & 198.8 & 201.4 & 186.5 \\
\hline average COD removal efficiency [\%] & $86.4(3.4)$ & $86.3(3.5)$ & $85.3(6.7)$ & $89.6(2.6)$ & $87.6(4.2)$ & $85.1(5.0)$ & $80.9(10.1)$ \\
\hline average sludge growth [mg $\mathrm{L} \cdot \mathrm{d}]$ & 100.0 & 87.5 & 87.5 & 125.0 & 125.0 & 87.5 & 100.0 \\
\hline approx. average yield of sludge [\%] & 76.5 & 66.8 & 67.6 & 61.0 & 62.9 & 43.4 & 53.6 \\
\hline
\end{tabular}


of $\mathrm{SV}_{30}$ and SVI values of the plants. The values were less than $30 \%$ for $\mathrm{SV}_{30}$ for all the plants. However, we can see that both red and blue illumination plants' $\mathrm{SV}_{30}$ was degrading. The SVI values were plotted with MLSS values of the corresponding activated sludge. Again, the SVI values were less than $100 \mathrm{~mL} / \mathrm{g}$ for all the plants. The bulking phenomenon of activated sludge is a severe trouble in WWTPs and it is judged by SVI values. The range of 50-150 $\mathrm{mL} / \mathrm{g}$ is considered standard value of SVI and if it crosses $200 \mathrm{~mL} / \mathrm{g}$, then bulking and carry over are occurred. From our observations, we did not find any sign of carry over or bulking in any SBR plants. But as described earlier that the values of SVI as well as $\mathrm{SV}_{30}$ were degraded in red and blue LED illumination plants.

We observed the activated sludge of all plants by an optic

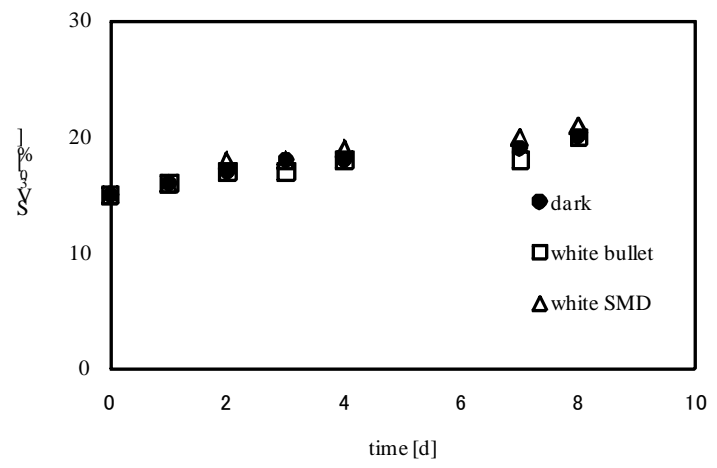

(a) $\mathrm{SV}_{30}$ values

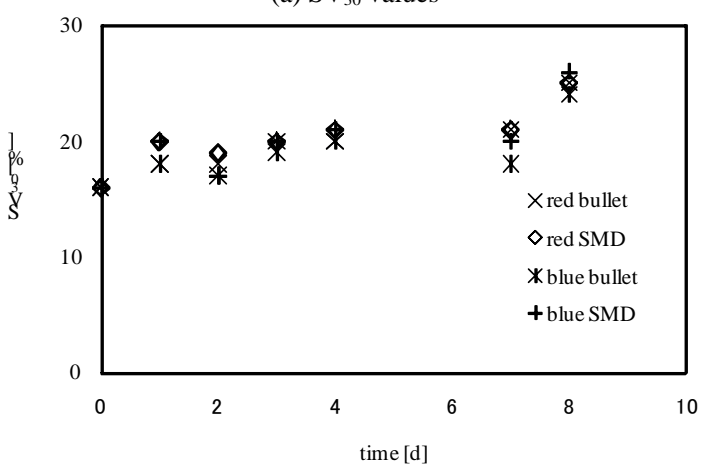

(b) $\mathrm{SV}_{30}$ values

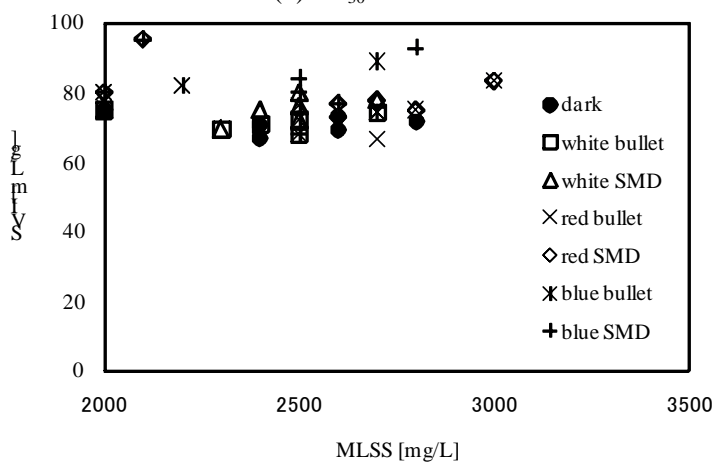

(c) SVI values

Fig. 8. Sedimentation characteristics of the activated sludge under LED illumination

microscope. Fig. 9 shows the snaps of the sludge. Except the seed sludge, all snaps were taken after the experimental period. It also showed that the formations of floc were disturbed in some SBR plants which were under blue or red LED illumination.
The relation between the sedimentation and the floc size of activated sludge can be understood by Stoke's law described below,

$$
v=g\left(\rho_{s}-\rho\right) d^{2} /(18 \mu)
$$

Here,

$v=$ settling velocity $[\mathrm{m} / \mathrm{s}]$

$\mathrm{g}=$ gravitational acceleration $\left[\mathrm{m} / \mathrm{s}^{2}\right]$

$\rho_{\mathrm{s}}=$ mass density of sludge $\left[\mathrm{kg} / \mathrm{m}^{3}\right]$

$\rho=$ mass density of water $\left[\mathrm{kg} / \mathrm{m}^{3}\right]$

$\mathrm{d}=$ size of floc $[\mathrm{m}]$

$\mu=$ dynamic viscosity $[\mathrm{kg} / \mathrm{ms}]$

One can understand that for larger floc in water the sedimentation is better comparing to the smaller particles. Thus, from the microscopic view of activated sludge, as the

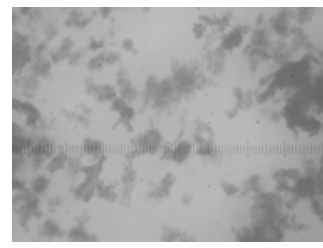

(a) seed sludge

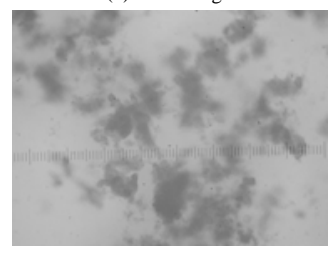

(c) white bullet

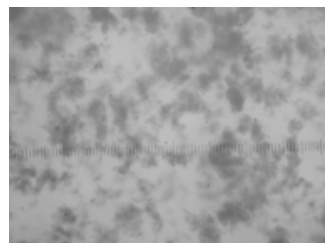

(e) red bullet

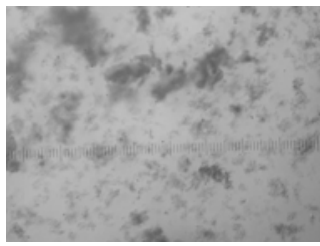

(g) blue bullet

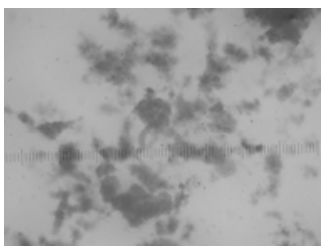

(b) dark

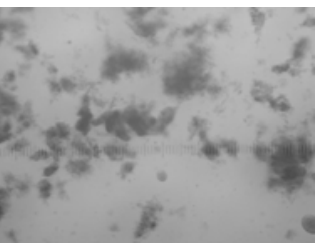

(d) white SMD

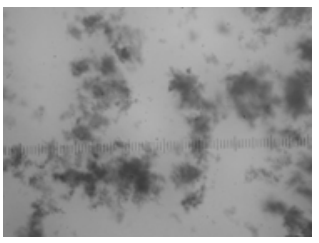

(f) red SMD

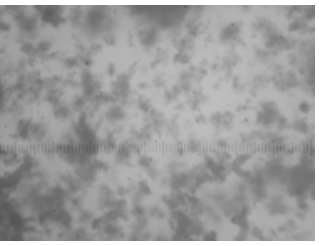

(h) blue SMD
Fig. 9. Microscopic view of activated sludge

size of floc was smaller in blue and red illumination comparing to seed sludge, the degradation in $\mathrm{SV}_{30}$ of them can be understood. However, more observations and research works are needed to understand the reasons for smaller floc in some LED illumination on activated sludge. Further works and observations are being carried out to understand the behavior of activated sludge growth under LED illumination.

\section{Conclusion}

Novel experiments were carried out to understand the activated sludge growth under various kinds of LED illumination. We used SBR plants in a constant temperature of water bath. Two types of white, blue and red LEDs were used as illuminating sources to the activated sludge. Our 
experiments confirmed that activated sludge could grow under LED illumination. The experiment results showed that there was no difference in the values of $\mathrm{pH}$ and COD removal properties of the sludge. But the growth of activated sludge was different for certain frequency (i.e. colors of LED) of LED. Sludge growth was affected by LED illumination for both bullet type and SMD type of LEDs. The sludge growth was retarding under LED illumination. Again, the floc size of activated sludge became smaller comparing to the seed sludge after the red and blue LED illumination of the relevant plants. The smaller size of the floc degraded the sedimentation properties of activated sludge. Further experiments were needed to learn and understand the biological changes in activated sludge under LED illumination.

\section{REFERENCES}

[1] Y. Wei, R. T. Van Houten, A. R. Borger, D. H. Eickelboom, and Y. Fan, "Minimization of excess sludge production for biological waste water treatment," Wat. Res., vol. 37, no. 18, pp. 4453-4467, May 2003.

[2] T. Yoshida, ed., Technologies for Minimization of Sludge and Reduction of Sludge, NTS, Tokyo, 2000 (in Japanese).

[3] Y. Sawada, S. Nagashima, T. Uchida, N. Kawashima, S. Takeuchi, M. Akita, and H. Nagaoka, "Basic study on sludge concentration and dehydration with ultrasonic exposure,” Jpn. J. Appl. Phys., vol. 44, no. 6B, pp. 4678-4681, May 2005.

[4] M. Kabir, M. Suzuki, and N. Yoshimura, "Reduction of Excess Sludge by Ferrite Particles,” Jpn. J. Wat. Treat. Biol., vol.43, no.4, pp.189-197, August 2007.

[5] M. Kabir, M. Suzuki, and N. Yoshimura, "Reduction of Excess Sludge by Magneto-Ferrite Treatment: Observation on Lab Scale WWTPs," IEEJ Trans.Elec. Electron. Engg., vol.4, no. 4, pp. 584-586, April 2009.

[6] M. Kabir, M. Suzuki, and N. Yoshimura, "Excess Activated Sludge Reduction by Using Electromagnets and Ferrite Particles,” IEEJ Trans. Elec. Electron. Engg., vol.7, no. 2, pp. 220-224, February 2012.

[7] Y. Miyoshi, "Ideas and techniques of sewage and wastewater treatment," Ohmsha , Tokyo, 2006 (in Japanese).

[8] W.W. Eckenfelder, and P. Grau, ed., Activated sludge process design and control: Theory and practice, Technomic Publishing Co. Lancaster, 1998.

[9] N. Fukuda, "Manipulatation of plant growth by light," Tsukuba Forum, vol.80, pp.3-6, May 2008 (in Japanese)

[10] S. Sawayama, T. Yagishita, and K. Tsukuhara, "Lighted Upflow Anaerobic Sludge Blanket,” J. Bioscience Bio Engg., vol.87, no.2, pp.258-260, May 1999.

[11] R. Miura, M. Kabir, M. Suzuki, and N. Yoshimura, "Effect of LED illumination on Activated Sludge Growth,” Proc. 2011 IEEJ Annual Meeting, no. 4, p. 371, March 2011(in Japanese).

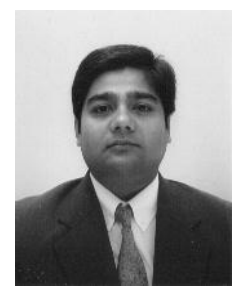

Mahmudul Kabir is a lecturer at Graduate School of Engineering and Resource Science, AkitaUniversity, Japan. He was born in Bogra, Bangladesh (1974) and completed his High School education in Bangladesh. He received his B.E., M.E. and Ph.D. degrees in Electrical and Electronic Engineering from Akita University in 2000, 2002 and 2005 respectively. He is a member of the IEE of Japan, the Institute of Electrostatics Japan and Japanese Society of Water

Treatment Biology.

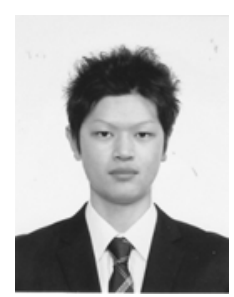

Ryutaro Miura was born on November 21, 1988 Akita, Japan. He graduated from Electrical and Information Engineering, Akita National College of Technology in 2009.

He received B.E. in Electrical and Electronic Engineering from Akita University in 2011.

Currently he is enrolled in graduate Program of the same University. He is working with indoor LED illumination.

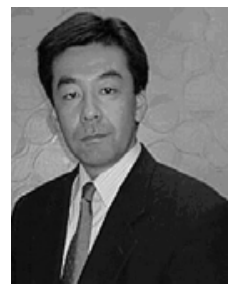

Masafumi Suzuki was born in Akita, Japan, on June 5, 1962. He received the B.E., and M.E. degrees in Electric Engineering from Akita University, Akita Japan, in 1985 and 1987, respectively. He received the D.Eng. Degree from Hokkaido University in1988. He is a professor of the Department of Electric and Electronic Engineering, Graduate School of Engineering and Resource Science, Akita University. His research work is on computer simulation such as design of ceramic varistor using electric equivalent circuit and various illuminating simulation. $\mathrm{He}$ is a member of the IEE of Japan, The Illuminating Engineering Institute of Japan, The Institute of Electrostatics Japan and The Society of Materials Engineering for Resources of Japan.

Noboru Yoshimura received his B.E. and M.E. from Akita University in

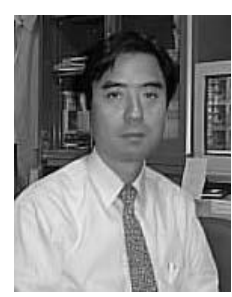
1967 and 1969, respectively and Dr. Degree from Nagoya University in 1975. He joined Akita University in 1969. He became a professor in 1983 and the Dean of Mining College of Akita University in 1995. He is the President of Akita University. He worked in Clarkson University of USA as a visiting scholar from 1978 to 1979 and as a visiting professor in 1989. He received paper award from IEE of Japan in 1984. He is now advisory professor of Xi'an Jiaotong University in China and had been president of The Society of Material Engineering for Resource of Japan until 1999. His research interests include organic dielectric materials, dielectric and semi-conductive ceramics. He is a member of IEEE, The Institute of Electrostatics Japan, The Illuminating engineering of Institute of Japan and other several Institutes and Societies. 